\title{
Inter Simple Sequence Repeats (ISSR) Marker based Genetic Diversity Analysis in White Yam (Dioscorea rotundata Poir.)
}

\author{
Parvathy Harikumar* and M.N. Sheela \\ Department of Crop Improvement, ICAR-Central Tuber Crops Research Institute, \\ Thiruvananthapuram, Kerala, India \\ *Corresponding author
}

\section{A B S T R A C T}

\section{Keywords}

White yam, ISSR

Markers, Genetic

diversity, Euclidean

distance, Hobs

value and PIC value

Article Info

Accepted:

04 October 2019

Available Online:

10 November 2019
Diversity in crops provides opportunity for plant breeders to develop new and improved cultivars with desirable characteristics, genetic improvement for existing varieties thus meet subsistence food requirement. DNA marker is reliable in genetic diversity study due to variations at sequence level, not influenced by environment and its expression in all tissues. Marker used in our study is Inter Simple Sequence Repeats (ISSR) for 30 different accessions of white yam including dwarf, semi dwarf and tall. Cluster analysis was done based on Euclidean distance of 30 accessions for ISSR, Dendrogram showed the partition of most of the dwarf and tall genotypes in to two different clusters and semi dwarf comes under the dwarf cluster. The ISSR primers produced an average of six polymorphic alleles with a mean Hobs and PIC values of 0.738 and 0.707 respectively. The higher PIC and Hobs values obtained in the present study for ISSR markers indicate high variability of population studied. Hence, ISSR markers can be used as a strong tool in elucidating genetic diversity in yams. Present study also identified a high yielding ( $8 \mathrm{~kg} / \mathrm{plant})$, highly divergent white yam genotype named DR17 that could be used for genetic improvement of white yam for future population.

\section{Introduction}

Yams are considered as crops of ancient origin which were cultivated even before 5000 BC. They are members of genus Dioscorea which produces tubers, bulbils or rhizomes having economic importance Lawton and Lawton (1969). As reported by FAO (2007), yam is cultivated in 50 tropical countries with annual production of 52 million tons. The most important part of yams is tuber and Greater yam, white yam, lesser yam and aerial yam are the major edible yams grown in India. The most important yam on worldwide basis is Dioscorea rotundata Poir (White yam or white guinea yam) grown on larger area 
compared to other yam species Waitt (1961). They are consumed as staple food and are rich in starch and energy, including higher values of protein and substantial amount of vitamins like thiamine, riboflavin and ascorbic acid and minerals like calcium, phosphorous and iron, with some identified medicinal properties too.

The lack of knowledge about the origin, diversity and genetics of these species has extremely limited the effectiveness of genetic improvement programmes Arnau et al., (2010). Major constraint on breeding programme of yam is that large number of varieties does not flower or if flowered, produce only reduced number of flowers. This is due to exclusive vegetative propagation over a long time and it is one of the problematic genera for cytogenetic studies because of the small size of the chromosomes, sticky nature and their satellites get confused as chromosomes due to same length. The acquisition of knowledge about the genetic diversity of the species at both agronomic and cytogenetic levels is essential for the effective genetic improvement programme. Hence considering this background, present study aims at revealing genetic diversity in 30 genetically important but different accessions of white yam that belongs to dwarf, semi dwarf and tall varieties using 15 ISSR primers and identifying highly variable variety from these accessions.

\section{Materials and Methods}

\section{Plant materials}

The plant material used in the present study were drawn from thirty accessions of tall, dwarf and semi dwarf varieties of $D$. rotundata which were maintained in the field gene bank of ICAR-CTCRI. The samples studies were belonging to three different genotypes as mentioned and comprising of 15 tall, 14 dwarf and one semi dwarf cultivar.

\section{DNA isolation and quantification}

DNA was extracted from fresh and tender young leaves of all the yam varieties studied using modified protocol of Doyle \& Doyle, 1987. Young leaves collected were weighed of about 100-200mg. Grind it in pestle and mortar using liquid nitrogen along with addition of little amount of Polyvinyl pyrrolidine. Added $1 \mathrm{ml}$ of extraction buffer and transferred to autoclaved $2 \mathrm{ml}$ eppendorf tubes and added 10ul Proteinase K. Vortexed and incubated it at $37^{\circ} \mathrm{C}$ for 30 minutes with intermittent shaking. Centrifuged at10,000 rpm for 15 minutes at room temperature and supernatant was collected. Collected supernatant was mixed with equal volume of chloroform:isoamylalcohol. Centrifuged at $10,000 \mathrm{rpm}$ for 10 minutes at room temperature. Supernatant collected and chloroform:isoamylalcohol extraction was repeated. Supernatant in fresh eppendorf tubes were mixed with 0.8 volume isopropanol to precipitate the DNA. Pelletized the DNA at $10,000 \mathrm{rpm}$ for 10 minutes and the pellet was saved and washed with $70 \%$ ethanol twice. Dried it on oven for 5-10 minutes to allow ethanol to vaporize and added TE buffer and stored at $-20^{\circ} \mathrm{C}$ refrigerator. All the samples were checked for DNA in $0.8 \%$ agarose gel and confirmed. Isolated DNA quantified using spectrophotometer (Systronics, India) at 260 and $280 \mathrm{~nm}$ to ensure its yield and purity.

\section{ISSR Marker based genetic diversity analysis}

The primers to be used in the present study (Table 1) that showing high polymorphic values in Dioscorea species were selected from literature study and the oligos were ordered and shipped (Integrated DNA Technologies, Inc) as lyophilized form to ICAR-CTCRI. The samples were amplified in thermal cycler using 15 different ISSR primers. The optimum amplifying conditions 
were standardized (Table 2 and 3). The amplified products were separated on $2 \%$ agarose gel along with $1 \mathrm{~Kb}$ and $100 \mathrm{bp}$ ladders to identify molecular weight of obtained bands. The results were photographed on a digital gel documentation and image analysis system.

\section{DATA analysis and statistics performed}

Reproducible bands were scored visually and validated to detect polymorphism using PIC calculator. A binary matrix of presence/absence was obtained from gels for each primer. The data matrix created in excel format was used as the input for cluster analysis. Estimation of genetic diversity parameters results in an overview of the genetic variability. Jaccard's similarity coefficient was calculated for use in clustering analysis by Unweighted Pair-group method with Arithmetic Average (UPGMA). Jaccard's similarity coefficient was calculated for use in clustering analysis by Unweighted Pair-group method with Arithmetic Average (UPGMA). Codes written in the $\mathrm{R}$ statistical language (http://www.rproject. org) used for analysis and the GLIMMIX procedure from SAS (2007) and DARwin5.5 (Perrier and Jacquemoud- Collet, 2006) were also used. The $\mathrm{R}$ statistical package was used for hierarchal cluster analysis based on Euclidean distance. Dendrogram grouping the 30 accessions based on ISSR marker, was constructed based on complete linkage method using Jaccard's distance as well as Dice coefficient on employing bootstraps using DarWin6.0 package.

\section{Results and Discussion}

The amplicons obtained after the ISSR analysis of 30 accessions using the selected primers were initially resolved in two per cent agarose gel. Genetic characteristics of the fifteen ISSR markers used to analyze the white yam accessions includes, total number of bands per ISSR primer ranged from 1 $\left.(\mathrm{ACC})_{6} \mathrm{Y}\right)$ to 10 (UBC 825). The primers UBC 809, UBC 827 and UBC 864 recorded nine bands followed by UBC 810 ( 8 bands). The primers UBC 808, UBC 811, (GA) 9 AC and UBC 817 recorded seven bands. The lowest number of bands was recorded by $(\mathrm{ACC})_{6} \mathrm{Y}$ (1) followed by (GA) ${ }_{9} \mathrm{AT}, \mathrm{UBC} 818$ and UBC 14 with three bands. UBC 825 that recorded the highest number of bands also recorded the highest number of polymorphic bands (10) followed by UBC 827 with UBC 864 with nine bands. In the case of primer UBC 810 , all the eight bands were found to be polymorphic. The polymorphism of the ISSR primers studied ranged from $77.78 \%$ to $100 \%$. UBC 809 recorded the lowest polymorphism (77.78\%) among the primers followed by UBC 811 (85.71\%). The Observed heterozygosity value (Hobs) of the ISSR primers ranged between $0\left((\mathrm{ACC})_{6} \mathrm{Y}\right)$ to 0.88 (UBC 825 and UBC 864). For most of the ISSR primers studied Hobs was found to be $>0.8$. Among the primers, the $(\mathrm{GA})_{9} \mathrm{AT}$ and UBC 818 recorded lower Hobs values of 0.5954 and 0.5448 respectively.

The polymorphism Information content (PIC) of the primers ranged from 0.8719 (UBC 864) followed by UBC 825(0.868), UBC 827 (0.8641) and UBC 809 (0.8601) (Fig. 1). The primers, UBC 818, (GA) ${ }_{9} \mathrm{AT}$, UBC 14 and (ACC) ${ }_{6}$ Y recorded lower PIC content of $<0.6$. The PIC and Hobs values of the ISSR primers studied were given in Figure 1. In the present study, the ISSR primers produced an average of six polymorphic alleles with mean Hobs and PIC values of 0.738 and 0.707 respectively. The result showed that ISSR markers can be used as an excellent tool for genetic variability study in white yam.

Based on ISSR data, the genotypes formed four clusters at 0.4 dissimilarity index (Fig. 2). Cluster 1 has only one genotype i.e.V20 
(DR17) and was found to be highly divergent than all other genotypes, formed as an outlier. The cluster 2 has two genotypes V23 \& V24. Cluster 3 is the biggest one with twenty four genotypes and they were grouped in to two sub clusters $3 \mathrm{a} \& 3 \mathrm{~b}$. The cluster 4 has three genotypes and was sub clustered in to two groups. The clustering pattern based on ISSR markers is given in Figure 2. Dendrogram showed the partition of most of the dwarf and tall genotypes in to two different clusters. Semi dwarf comes under the cluster of dwarf genotypes.

Table.1 List of ISSR primers used in the present study

\begin{tabular}{|c|c|}
\hline Sl. No & Primer name \\
\hline $\mathbf{1}$ & UBC 808 \\
\hline $\mathbf{2}$ & UBC 809 \\
\hline $\mathbf{3}$ & UBC 810 \\
\hline $\mathbf{4}$ & UBC 811 \\
\hline $\mathbf{5}$ & UBC 817 \\
\hline $\mathbf{6}$ & UBC 825 \\
\hline $\mathbf{7}$ & UBC 827 \\
\hline $\mathbf{8}$ & UBC 848 \\
\hline $\mathbf{9}$ & UBC 864 \\
\hline $\mathbf{1 0}$ & UBC 818 \\
\hline $\mathbf{1 1}$ & UBC 836 \\
\hline $\mathbf{1 2}$ & $(\mathrm{GA})_{9}$ AC \\
\hline $\mathbf{1 3}$ & $(\mathrm{GA})_{9}$ AT \\
\hline $\mathbf{1 4}$ & UBC 14 \\
\hline $\mathbf{1 5}$ & $(\mathrm{ACC})_{6} \mathrm{Y}$ \\
\hline
\end{tabular}

Table.2 Components of ISSR PCR used in the present study

\begin{tabular}{|c|c|c|c|}
\hline Components & $\begin{array}{c}\text { STOCK } \\
\text { Conc. }\end{array}$ & $\begin{array}{c}\text { Required } \\
\text { Conc. }\end{array}$ & $\begin{array}{c}\text { Volume for one } \\
\text { reaction }(\mathbf{2 0} \boldsymbol{\mu l})\end{array}$ \\
\hline Buffer with 15mM & $10 \mathrm{X}$ & $1 \mathrm{X}$ & $2 \mu \mathrm{L}$ \\
\hline Mgcl $_{\mathbf{2}}$ & $25 \mathrm{Mm}$ & $1 \mathrm{Mm}$ & $0.8 \mu \mathrm{L}$ \\
\hline $\mathbf{d N T P}$ & $2 \mathrm{mM}$ & $2 \mathrm{mM}$ each & $0.5 \mu \mathrm{L}$ \\
\hline Primer & $10 \mu \mathrm{M}$ & $0.3 \mu \mathrm{M}$ & $0.6 \mu \mathrm{L}$ \\
\hline DNA template & $10 \mathrm{ng} / \mu \mathrm{L}$ & $20 \mathrm{ng}$ & $2 \mu \mathrm{L}$ \\
\hline Taq DNA Polymerase & $2 \mathrm{U} / \mu \mathrm{L}$ & $1 \mathrm{U}$ & $0.5 \mu \mathrm{L}$ \\
\hline $\mathbf{d H}_{\mathbf{2}} \mathbf{O}$ & - & - & $13.6 \mu \mathrm{L}$ \\
\hline & Total & & $20 \mu \mathrm{L}$ \\
\hline
\end{tabular}


Table.3 Protocol of ISSR PCR used in the present study

\begin{tabular}{|c|c|c|c|c|}
\hline Cycling step & Temperature $\left({ }^{\circ} \mathbf{C}\right)$ & Time & Ramping rate & Cycles \\
\hline Enzyme activation & 94 & $5 \mathrm{~min}$ & & 1 \\
\hline Denaturation & 94 & $30 \mathrm{~s}$ & \multirow{2}{*}{$\sim{ }^{\circ} \mathrm{C} / \mathrm{S}$} & 35 \\
\hline Annealing & 56 & $1 \mathrm{~min}$ & & 1 \\
\hline Extension & 72 & $1 \mathrm{~min}$ & & 1 \\
\hline Final Extension & 72 & $10 \mathrm{~min}$ & & 1 \\
\hline Hold & 4 & Infinite & & \\
\hline
\end{tabular}

Fig.1 Polymorphism Information content of the ISSR primers among white yam genotypes

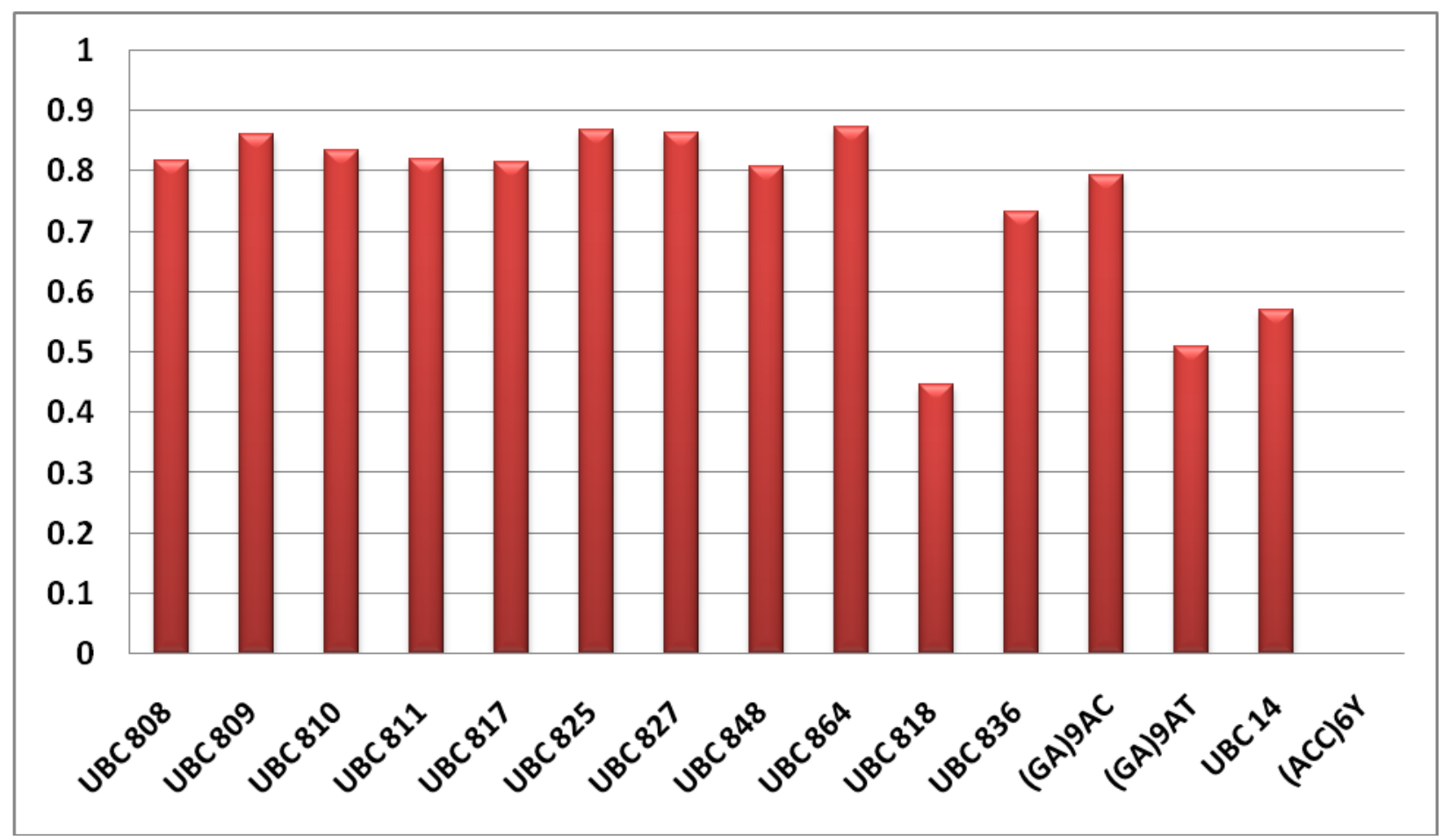

Fig.2 Cluster dendrogram constructed based on ISSR marker analysis

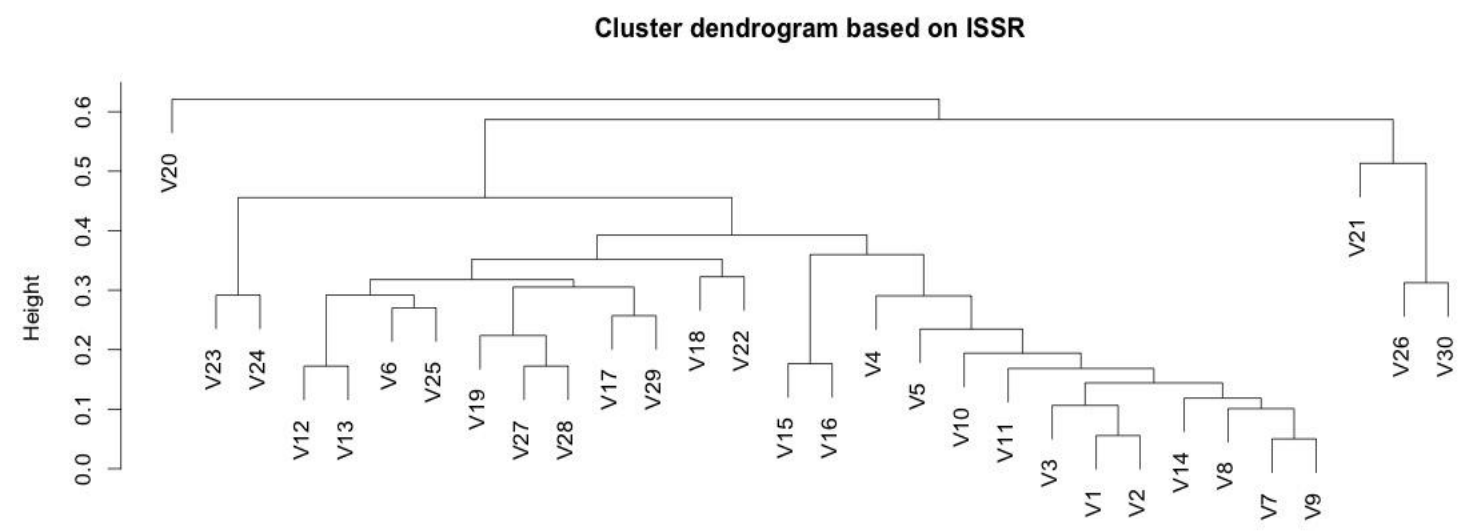


On literature search different molecular markers were studied to identify genetic diversity in yams including genetic diversity analysis of yams (Dioscorea spp.) cultivated in China using ISSR and SRAP markers. In this study, 11 inter simple sequence repeat (ISSR) and 60 sequence related amplified polymorphism (SRAP) techniques were used to assess genetic diversity within 21 yam landraces from seven cultivated populations and observed high level of polymorphism among these landraces, specifically, $95.3 \%$ for ISSR and $93.5 \%$ for SRAP Wu et al., (2014). The genetic diversity of 52 genotypes of yam germplasm from Sierra Leone was accessed using 14 SSR primers. High diversity of 0.650 was noted among genotypes studied Norman et al., (2012).

Clonal diversity and estimation of relative clone age in yam (Dioscorea rotundata) had done as an application in agro biodiversity studies. Evolutionary history of yam and intraclonal diversity is studied using 12 microsatellite markers Scarcelli et al., (2013). Genetic diversity of Dioscorea dumetorum (Kunth) Pax using Amplified Fragment Length Polymorphisms (AFLP) and cpDNA was studied Sonibare et al., (2010). Siqueira et al., (2014) studied water yam (Dioscorea alata L.) diversity pattern with SSR and morphological markers. Genetic diversity and structure analysis among commercial and local varieties of water yam (Dioscorea alata L.) in Brazil using microsatellite and morphological markers.12 SSR primers were used to generate DNA profiles of 72 local varieties and 17 commercial accessions of water yam collected from four different regions in Brazil. High polymorphism was found with $100 \%$ polymorphism observed for 11 primers and a discriminating power value of 0.92 , on an average. ISSR primers were selected based on previous reports in yams.

For preliminary screening of ISSR, 19 ISSR primers were used of which, only 15 were selected based on their polymorphism and repeatability. Fifteen polymorphic ISSR markers were used for the molecular characterization of selected white yam genotypes. The total number of bands per ISSR primer ranged from $1\left((\mathrm{ACC})_{6} \mathrm{Y}\right)$ to 10 (UBC 825). In the present study, the ISSR primers produced an average of six polymorphic alleles with a mean Hobs and PIC values of 0.738 and 0.707 respectively. However, The polymorphic information content measures the informativeness related to the expected heterozygousity (HE) and can also be estimated from allele frequencies. The higher PIC and Hobs values obtained in the present study for the ISSR markers indicate the high variability of the population studied. It also indicated the usefulness of the ISSR markers identified, they can be used in elucidating genetic diversity among yams in future. From the study identified a high yielding $(8 \mathrm{~kg} /$ plant), highly divergent white yam genotype named DR17 and that could be used for the genetic improvement of white yam in future.

\section{References}

Arnau, G., Abraham, K., Sheela, M. N., Chair, H., Sartie, A. and Asiedu, R. 2010. Yams. In: Handbook of Plant Breeding, Root and Tuber Crops. 7: Pp 127-148.

FAO. (2007). FAOSTAT Database online, http//faostata.fao.org.

Lawton, J. R. and Lawton, J. R. S. 1969. The development of tuber in the seedlings of five species of Dioscorea from Nigeria. Bot. J. Linn. Soc. 62: 223.

Norman, P. E., Tongoona, P., Danson, J. and Shanahan, P. E. 2012. Molecular characterization of some cultivated yam (Dioscorea spp.) genotypes in Sierra Leone using simple sequence repeats. Intl. J. Agron. Plant. Prod. 3: 265-273.

Scarcelli, N., Couderc, M., Baco, N. M., Egah, 
J. and Vigouroux, Y. 2013. Clonal diversity and estimation of relative clone age: application to agrobiodiversity of yam (Dioscorea rotundata). BMC Plant Biol. 13: 178188.

Siqueira, M. B. V. M., Bonatelli, L. M., Günther, T., Gawenda, I., Schmid, J. K., Pavinato, C. A. V. and Veasey, A. E. 2014. Water yam (Dioscorea alata L.) diversity pattern in Brazil: An analysis with SSR and morphological markers.Genet. Resour. Crop. Evol. 61: 611-624.

Sonibare, A. M., Asiedu, R. and Albach, C. D.
2010. Genetic diversity of Dioscorea dumetorum (Kunth) Pax using amplified fragment length polymorphisms (AFLP) and cpDNA. Biochem Sys. Ecol. 38: 320-334.

Waitt, A. W. 1961. Key to some Nigerian yam varieties. Memo Fed. Dept. Agric. Res., Nigeria.

Wu, G. Z., Li, X. X., Lin, C. X., Jiang. W., Tao, M. Z., Mantri, N., Fan, Y. C. and Bao, Q. X. 2014. Genetic diversity analysis of yams (Dioscorea spp.) cultivated in China using ISSR and SRAP markers. Genet. Resour. Crop. Evol. 61: 639-650.

\section{How to cite this article:}

Parvathy Harikumar and Sheela, M.N. 2019. Inter Simple Sequence Repeats (ISSR) Marker based Genetic Diversity Analysis in White Yam (Dioscorea rotundata Poir.). Int.J.Curr.Microbiol.App.Sci. 8(11): 375-381. doi: https://doi.org/10.20546/ijcmas.2019.811.047 